\title{
CORRIGENDUM
}

\section{Identification and validation of biomarkers associated with acute and chronic graft versus host disease}

SS Ahmed, XN Wang, J Norden, K Pearce, E El-Gezawy, S Atarod, I Hromadnikova, M Collin, E Holler and AM Dickinson

Bone Marrow Transplantation (2016) 51, 890; doi:10.1038/bmt.2016.125

Correction to: Bone Marrow Transplantation (2015) 50, 1563-1571; doi:10.1038/bmt.2015.191; published online 14 September 2015

Since the publication of this article, it has been noted that author E El-Gezawy was missing a second affiliation. The updated author affiliations can be found below.

SS Ahmed ${ }^{1,2}$, XN Wang ${ }^{1,2}$, J Norden ${ }^{1}$, K Pearce ${ }^{1}$, E El-Gezawy ${ }^{1,3}$, S Atarod ${ }^{1}$, I Hromadnikova ${ }^{4}, \mathrm{M}$ Collin ${ }^{1}, \mathrm{E}$ Holler $^{5}$ and AM Dickinson ${ }^{1,2}$

${ }^{1}$ Haematological Sciences, Institute of Cellular Medicine, Newcastle University, Newcastle-upon-Tyne, UK

\author{
${ }^{2}$ Alcyomics Ltd, Newcastle-upon-Tyne, UK \\ ${ }^{3}$ Clinical Pathology Department, Faculty of Medicine, Assiut \\ University, Assiut, Egypt \\ ${ }^{4}$ Third Faculty of Medicine, Charles University, Prague, Czech \\ Republic
}

${ }^{5}$ Regensburg University Hospital, Department of Hematology and Oncology, Regensburg, Germany

The authors would like to apologise for this error. 